\title{
Erythrocyte Membrane Proteins Reactive with Human (Warm-reacting) Anti-Red Cell Autoantibodies
}

\author{
John P. Leddy, Josie L. Falany, Gregg E. Kissel, Sherry Ting Passador, and Stephen I. Rosenfeld \\ Clinical Immunology/Rheumatology Unit, Department of Medicine, University of \\ Rochester School of Medicine and Dentistry, Rochester, New York 14642
}

\begin{abstract}
Immunoglobulin G (IgG) autoantibodies of 20 patients with autoimmune hemolytic anemia (AHA) were used in immunoaffinity assays with surface-radioiodinated human red blood cells (RBCs), and detergent-solubilized products were analyzed by SDS-PAGE/autoradiography. Four membrane proteins were identified as candidate autoantigens: a nonglycosylated polypeptide with an apparent molecular mass of $34 \mathrm{kD}$ (p34) that was expressed in all available $R B C$ phenotypes except $R_{h_{\text {null }}}$ but differed consistently in apparent molecular mass from the 32kD Rh(D) polypeptide coisolated by IgG allo-anti-D; a heterogenous 37-55-kD glycoprotein, also deficient in $\mathbf{R} \mathbf{h}_{\text {null }} \mathbf{R B C s}$, which disappeared after deglycosylation by $\boldsymbol{N}$-glycanase, with the appearance of a sharp, new $\sim 31-\mathrm{kD}$ band distinct from p34 and from Rh(D) polypeptide; a $\sim 100$-kD major membrane glycoprotein identified by immunoblotting as the band 3 anion transporter; and glycophorin A (GPA), also confirmed by immunoblotting. GP37-55 was not seen in the absence of p34, and both proteins are likely to be members of the $R h$ family. Indeed, a 34-kD polypeptide band and 37-55-kD polydisperse "smear," isolated concurrently from the same labeled RBCs by IgG allo-anti-e, were indistinguishable from their autoantibody-isolated counterparts and may well be the same protein identified at different epitopes by the auto- and allo-antibodies. Individual AHA patients' autoantibodies isolated p34 and gp37-55, alone or in combination with band 3 (nine cases); strong band 3 alone (five cases); and combinations of band 3 with GPA ( six cases). The autoantibodies of three additional patients whose AHA had been induced by $\alpha$-methyldopa also isolated p34 and gp37-55. (J. Clin. Invest. 1993. 91:16721680.) Key words: erythrocyte autoantigens $\bullet$ autoimmune hemolytic anemia
\end{abstract}

\section{Introduction}

Autoimmune hemolytic anemia (AHA) ${ }^{1}$ was one of the first human diseases to be recognized as an authentic autoimmune

A major portion of this work was presented at the Annual Meeting of the American Federation for Clinical Research, American Society for Clinical Investigation, and Association of American Physicians, Baltimore, MD, 1-4 May 1992 (1).

Address correspondence to John P. Leddy, M.D., Box 695, University of Rochester Medical Center, Rochester, NY 14642.

Received for publication 3 August 1992 and in revised form 13 November 1992.

J. Clin. Invest.

(C) The American Society for Clinical Investigation, Inc. 0021-9738/93/04/1672/09 \$2.00

Volume 91, April 1993, 1672-1680 disorder (2, 3). Although the effector mechanisms governing such antibody-mediated destruction of human red cells have been increasingly clarified over many years $(4,5)$, fundamental questions concerning the genesis of the erythrocyte-reactive autoantibodies have remained unanswered. With respect to the more common, "warm antibody" type of human AHA, knowledge of the red blood cell ( $R B C$ ) membrane structures with which such autoantibodies react had long been based mainly on serological (indirect antiglobulin) testing with human RBCs of rare phenotypes (for review see reference 6). These autoantibodies characteristically react with essentially all human RBCs and with the RBCs of higher (old world) primates but not with RBCs of other species (2). In a significant proportion of AHA patients, specificity of their autoantibodies for one or more determinants of the rhesus $(\mathrm{Rh})$ blood group had been deduced from serological observations including selectively weak or negative reactions with $R h_{\text {null }} R B C s$, which lack any known expression of the Rh complex (6-10); or selective or preferential reactivity with $\mathrm{RBCs}$ expressing known $\mathrm{Rh}$ antigens such as "e," "E," or "c," also present on the patient's own $\operatorname{RBCs}(2,6,8,9)$. The latter antibodies were usually found in combination with less well-defined autoantibodies. Cautious interpretation of these observations was warranted, however, by the knowledge that $R h_{\text {null }} R B C s$ have membrane anomalies other than deficiency of $\mathrm{Rh}$ antigens (11) and by the fact that careful serological analysis has suggested subtle differences between, e.g., auto-anti-e and allo-anti-e (12). Moreover, in many other AHA patients, the reactivity of their autoantibodies with $\mathrm{Rh}_{\text {null }} \mathrm{RBCs}$ and RBCs of "normal" phenotype was equally strong, suggesting that in these patients the autoantibodies recognized $\mathrm{RBC}$ determinants distinct from known components of the Rh complex (6-10). Furthermore, through the use of human RBCs selectively deficient in other blood group antigens, evidence has accumulated in selected AHA patients for autoantibody specificity against serologically defined, non-Rh RBC antigens such as $\mathrm{Wr}^{\mathrm{b}}$ (13), $\mathrm{En}^{\mathrm{a}}$ (14), LW (15), U (16), or antigens of the Kell blood group (17). Efforts to elucidate the biochemical nature of the RBC autoantigens in AHA were initiated by one of us (J. P. Leddy) $>20$ yr ago (18) but were set aside until more effective methods became available. More recent immunochemical studies have concluded that the major anion-transport protein, band 3 (19), or band 4.1 protein (20) serve as targets of these autoantibodies in AHA.

In this report we present evidence that four distinct membrane proteins may participate in the molecular composition of RBC autoantigens in AHA. Two appear to be minor RBC

1. Abbreviations used in this paper: AHA, autoimmune hemolytic anemia; $\alpha$-MD, alpha-methydopa; GPA, glycophorin A; IAT, indirect antiglobulin test; NC, nitrocellulose; $\mathrm{RBC}$, red blood cell; $\mathrm{Rh}$, rhesus blood group; RT, room temperature. 
proteins and members of the $\mathrm{Rh}$ family. The other two are major membrane glycoproteins, band 3 and glycophorin A (GPA).

\section{Methods}

Anti-red cell antibodies. The autoantibodies used were in the form of concentrated eluates from the RBCs of patients with warm-antibody AHA (Table I). After informed consent, blood was drawn into $0.01 \mathrm{M}$ EDTA and eluates were prepared either immediately or after no more than overnight storage at $4^{\circ} \mathrm{C}$. The patients' RBCs were washed six times ( $20 \mathrm{vol} / \mathrm{vol}$ packed RBCs) and membranes were prepared by lysis in digitonin, $0.25 \mathrm{mg} / \mathrm{ml}$ final concentration (Sigma Chemical Co., St. Louis, MO), as previously described (10). After five more washes of the membranes in cold saline, the antibodies were eluted in

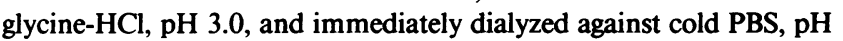
7.3. Up to five cycles of elution were required to dissociate all recoverable antibody. Indirect antiglobulin test (IAT)-positive eluates from the various cycles were pooled and concentrated by ultrafiltration. Patients were included in the study only on the basis of adequate strength of their eluates.

To prepare IgG anti-Rh(D) alloantibody eluates, group O RBCs, freshly obtained from healthy laboratory personnel whose probable $R h$ genotypes were $R_{1} R_{1}(\mathrm{CDe} / \mathrm{CDe})$ or $R_{1} R_{2}(\mathrm{CDe} / \mathrm{cDE})$, were washed and incubated $\left(37^{\circ} \mathrm{C}, 1 \mathrm{~h}\right)$ with commercial hyperimmune human anti-D (Hyp-Rho; Cutter Biologicals, Elkhart, IN; or Rho GAM; Ortho Pharmaceutical, Raritan, NJ) in the ratio of $10 \mathrm{ml}$ packed RBCs to $1 \mathrm{ml}$ anti-D. This was slight antibody excess. The resulting anti-Dcoated RBCs were then treated identically to autoantibody-coated RBCs. "Control eluates" were prepared by the same procedures from comparable numbers of unsensitized RBCs of the same healthy Coombs-negative donors. Eluates were stored at $-20^{\circ} \mathrm{C}$ until used. Human serum containing IgG anti-e alloantibody from an individual donor was obtained from Sero-Tec Biologicals (North Brunswick, $\mathrm{NJ}$ ).

Rabbit antisera to human erythrocyte band 3 (R334 and 1514B) were generously donated by Dr. Marguerite M. B. Kay (University of Arizona College of Medicine, Tucson, AZ). Murine IgG1 mAb to human glycophorin A ( 10 F7MN) (21) was provided by Dr. R. J. Looney (University of Rochester) as culture supernatant from a hybridoma obtained from American Type Culture Collection (Rockville, MD).

Serological testing, by direct and indirect antiglobulin reactions, was performed by standard methods as described (10). Comparative reactivity of concentrated AHA eluates with normal and Rh null RBCs was determined by serial twofold titration using indirect antiglobulin reactions. The eluates for these assays were not always the fully concentrated eluates used in the radio-immunoprecipitation assays described below. It was our practice to set aside a small volume of partially concentrated eluate expressly for serological testing, to minimize freezing and thawing of the fully concentrated eluate.

Surface radioiodination of erythrocytes. Normal RBCs were freshly obtained (in citrate) from healthy group $O$ donors of probable $R \mathbf{R}$ genotypes $R_{1} R_{1}, R_{1} R_{2}, R_{2} R_{2}(c D E / c D E)$, or $\pi$ (ce/ce), immediately sedimented to allow aspiration of buffy coat, and washed twice in cold $0.15 \mathrm{M}$ saline with further removal of the uppermost cellular layer. The RBCs were placed in Alsever's solution, electronically counted (together with monitoring of leukocyte and platelet contamination), and used either the same day or, more commonly, after overnight storage at $4^{\circ} \mathrm{C}$. Group $\mathrm{O} \mathrm{Rh}_{\text {null }}$ red cells from two sibling donors ( $\mathrm{Sa}$ and $\mathrm{Na}$ ) were generously provided by Dr. Chantal Harrison, Blood Bank Director (University of Texas Health Sciences Center, San Antonio, TX). These cells were either freshly drawn, kept in their own plasma during shipping, and then placed in Alsever's solution or reconstituted from frozen storage. These alternative methods of handling did not alter the results.

For radiolabeling, $10^{9}$ previously washed RBCs in Alsever's solution were washed twice in cold $0.15 \mathrm{M} \mathrm{NaCl}$ and the packed $\mathrm{RBCs}$, after resuspension to $0.7 \mathrm{ml}$ in PBS, were added to flat-bottomed glass vials precoated with $50 \mu \mathrm{g}$ chloroglycouril (Iodo-Gen; Pierce Chemical Co., Rockford, IL). 1 mCi carrier-free $\mathrm{Na}^{125}$ I (Amersham Corp., Arlington Heights, IL) was added for $30 \mathrm{~min}$ at room temperature (RT) with gentle swirling every $10 \mathrm{~min}$. The labeled RBCs were immediately transferred to a clean $15-\mathrm{ml}$ conical tube containing $5 \mathrm{mM} \mathrm{KI}$ in PBS, washed twice more in $5 \mathrm{mM} \mathrm{KI} / \mathrm{PBS}$, transferred to a second clean tube, and washed once more in PBS. The packed cells were then brought to $0.4 \mathrm{ml}$ with PBS. Alternatively, the same volume of RBCs was radioiodinated using Iodo-Gen beads (Pierce Chemical Co.) and $300 \mu \mathrm{Ci}$ of $\mathrm{Na}^{125} \mathrm{I}$. By either procedure $\sim 140 \mu \mathrm{Ci}^{125} \mathrm{I}$ was bound per milliliter packed RBCs.

Immunoaffinity isolation of $R B C$ membrane proteins. Our general approach was adapted from earlier work on the $\mathrm{Rh}(\mathrm{D})$ protein $(22$, 23). In 0.65-ml microcentrifuge tubes (Click Seal; National Scientific Co., San Rafael, CA ), $50 \mu$ l labeled RBCs $\left(1.25 \times 10^{8}\right.$ cells $)$ plus $90 \mu 1$ PBS were incubated with $40 \mu \mathrm{l}$ AHA eluate (or with control eluate or anti-D eluate) for $90 \mathrm{~min}$ at $37^{\circ} \mathrm{C}$ on a rotator. The mixtures were transferred to 4-ml polycarbonate tubes (Sorvall Instruments Div., part of DuPont Co., Newtown, CT) and washed three times with cold PBS. The washed RBCs were resuspended in $0.05 \mathrm{ml}$ PBS and lysed by adding $1 \mathrm{ml}$ cold $5 \mathrm{mM}$ sodium phosphate, $\mathrm{pH} 8.0$, containing $1 \mathrm{mM}$ PMSF (Sigma Chemical Co.) and $10 \mathrm{mM}$ EDTA, with Vortex mixing (30 s) and standing $30 \mathrm{~min}$ on ice. Lysates were centrifuged for $30 \mathrm{~min}$ at $35,000 \mathrm{~g}$ at $4^{\circ} \mathrm{C}(\mathrm{RC} 2-\mathrm{B}, \mathrm{SS}-34$ rotor, Sorvall Instruments Div.) to pellet RBC ghosts, which were then washed twice with cold hypotonic phosphate. Packed washed ghosts were solubilized in $125 \mu$ l freshly prepared peroxide-free $2 \%$ Triton X-100 (Boehringer-Mannheim Corp., Indianapolis, IN) in cold PBS containing $1 \mathrm{mM}$ PMSF and 10 mM EDTA, with Vortex mixing for $10 \mathrm{~min}$ at RT. After centrifugation at $35,000 \mathrm{~g}$ for $30 \mathrm{~min}$, the immune complex-containing supernatants were transferred to $1.7-\mathrm{ml}$ microcentrifuge tubes (Click Seal) containing $25 \mu \mathrm{l}$ packed protein G-Sepharose beads (Zymed Laboratories Inc., South San Francisco, CA), which had been prewashed eight times with $2 \%$ Triton X-100 in PBS. After overnight incubation of the solubilized RBC antigen-antibody complexes with the beads on a rotator at $4^{\circ} \mathrm{C}$, the beads were washed twice with cold $2 \%$ Triton X-100 in PBS, twice with $1 \%$ Triton X-100 in PBS, and twice with $5 \mathrm{mM}$ phosphate, $\mathrm{pH} 8.0$. Substitution of goat anti-human IgG-Sepharose for protein G-Sepharose yielded comparable results.

The Sepharose pellets $(25 \mu \mathrm{l})$ were suspended in $25 \mu \mathrm{l}$ Laemmli sample buffer (24) containing $2 \%$ SDS and, in the experiments shown, $20 \mathrm{mM}$ DTT, and incubated at $100^{\circ} \mathrm{C}$ for $2 \mathrm{~min}$. After microcentrifugation, $20 \mu \mathrm{l}$ of each supernatant was applied to a gradient polyacrylamide slab gel in $0.1 \%$ SDS using a Mini-Protean system (Bio-Rad Laboratories, Richmond, CA). Two types of gradient gel proved most effective: $5-15 \%$ with a $37: 1$ acrylamide/bis ratio; and $8-16 \%$ with a 42:1 acrylamide/bis ratio. In some experiments on deglycosylation by $N$-glycanase (see below), a 10-20\% gradient gel was chosen. The completed gels were dried and analyzed by autoradiography using XAR-2 film (Eastman Kodak Co., Rochester, NY) with Cronex intensifying screens (DuPont Co., Wilmington, DE). The presence or absence of DTT did not alter the positions of the proteins under study. Radiolabeled ("rainbow") molecular weight markers (Amersham Corp.) included myosin $(200,000)$, phosphorylase b $(92,500)$, BSA $(69,000)$, ovalbumin $(46,000)$, carbonic anhydrase $(30,000)$, soybean trypsin inhibitor $(21,500)$, and lysozyme $(14,300)$. The apparent molecular mass of a given protein band was estimated graphically (25).

Immunoblotting. In selected experiments, radioiodinated RBC membrane proteins separated in SDS-PAGE gels were electrotransferred to nitrocellulose (Transphor TE-50; Hoefer Scientific Instruments, San Francisco, CA). The nitrocellulose membrane was blocked with 3\% BSA (2-3 h at RT) followed, in appropriate experiments, by sequential addition of 1:100 rabbit anti-band $3(2 \mathrm{~h})$ and 1:500 peroxidase-labeled goat anti-rabbit IgG (Kirkegaard \& Perry Laboratories, Inc., Gaithersburg, MD), ( $2 \mathrm{~h}$ ) or 1:10 mouse anti-GPA mAb and 1:250 peroxidase-labeled goat anti-mouse IgG (Kirkegaard \& Perry Laboratories, Inc.). Development was with 4-chloro-1-naphthol/hydrogen peroxide substrate (Bio-Rad Laboratories). Autoradiographic 


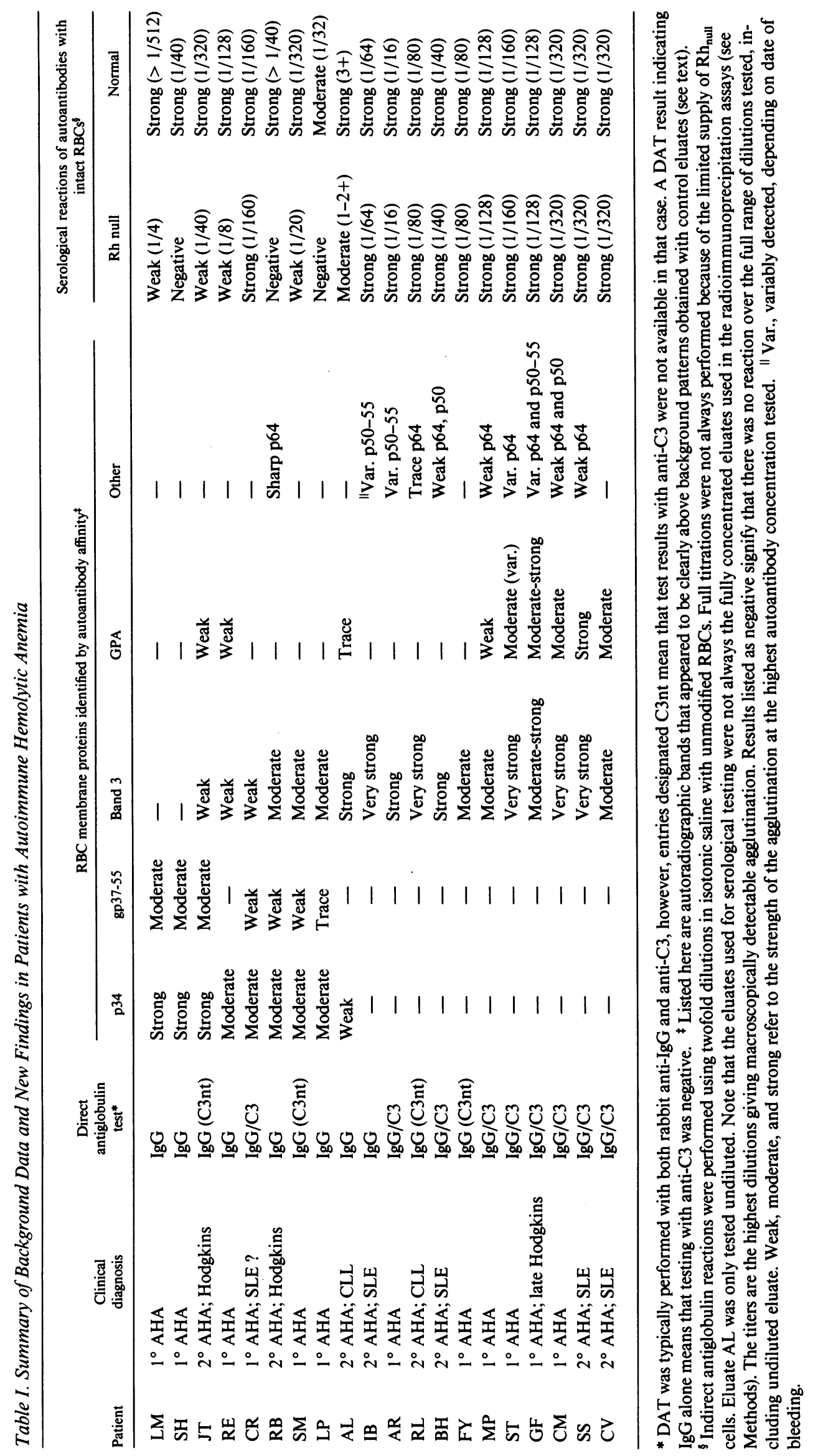


visualization of the same blot followed the procedures for direct autoradiography of the SDS-PAGE gels described above.

Deglycosylation. The effect of recombinant $N$-glycanase (Genzyme Corp., Cambridge, MA) could not be tested on RBC proteins that had been freshly eluted from protein $G$ beads because of enzyme inactivation by $1 \%$ SDS. Therefore, a procedure was devised for in situ digestion of the RBC proteins while still bound to the protein $\mathrm{G}$ beads (before SDS elution). Our standard immunoaffinity isolation protocol (see above) was followed through the final washings in 2 and $1 \%$ Triton $\mathrm{X}-100$, just before elution in SDS. At that point the beads were washed twice in cold "enzyme buffer" ( $20 \mathrm{mM}$ phosphate, $100 \mathrm{mM} \mathrm{NaCl}$ plus PMSF and EDTA, pH 7.6). To each sample $(25 \mu \mathrm{l})$ of pelleted beads was added $100 \mu \mathrm{l} N$-glycanase $(0.25 \mathrm{U})$ in enzyme buffer. Control pellets received buffer alone. Except for kinetic assays ( see below), the beads were incubated on a rotator for $4 \mathrm{~h}$ at $37^{\circ} \mathrm{C}$ followed by washing three times with cold buffer. The washed beads were then eluted in Laemmli buffer and the eluted proteins subjected to SDS-PAGE/autoradiography.

\section{Results}

$R h$-related membrane proteins. Two proteins in this category were isolated from surface-radioiodinated RBCs by AHA autoantibodies, one producing a dense autoradiographic band of 34 $\mathrm{kD}$ (p34) and the other a fainter, polydisperse "smear" (gp3755) (Fig. 1). 9 of our 20 AHA patients' autoantibodies mediated the isolation of p34 (Table I). (The mean measured $M_{\mathrm{r}}$ in these nine cases was $33.5 \mathrm{kD}$ ). In five of these patients ( $\mathrm{LM}$, SH, JT, RE, CR), p34 was the dominant band isolated (Table I). In the other four patients (RB, SM, LP, AL), the autoradiographs identified p34 plus at least one other relatively strong protein band of $95-100 \mathrm{kD}$ or of $\sim 41 \mathrm{kD}$, which, from evidence to be presented below, are band 3 and GPA, respectively. In dozens of experiments, p34 exhibited a small but very consistent difference in $M_{\mathrm{r}}$ from the $32-\mathrm{kD} \mathrm{Rh}(\mathrm{D})$ polypeptide coisolated from the same labeled RBCs using allo-anti-D (see Figs. 1-3). A 34-kD protein band corresponding to p34 was difficult to detect in autoradiographs of unmodified whole $\mathrm{RBC}$ lysates (one example is shown below, see Fig. $3 b$ ), suggesting that isolation of $\mathrm{p} 34$ by autoantibody-directed immuno-

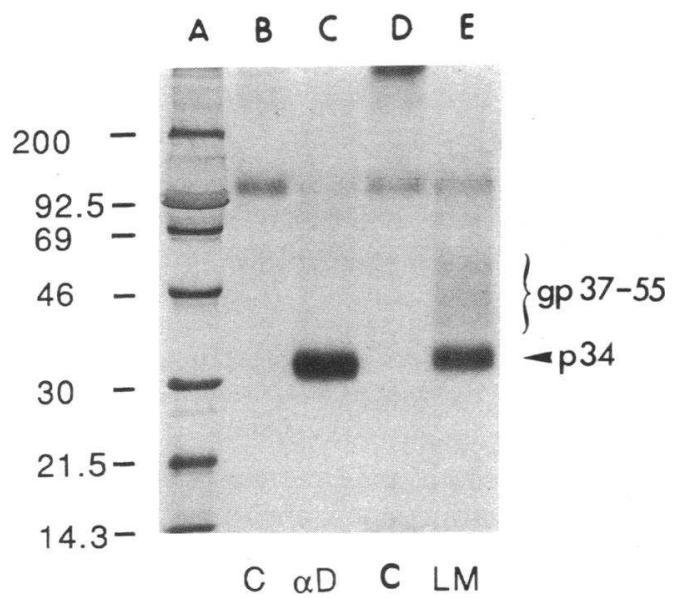

Figure 1. Autoradiograph of SDS-PAGE separation of ${ }^{125}$ I-labeled membrane proteins immunoaffinity isolated from normal $(\mathrm{O} \mathrm{CDe} /$ $\mathrm{cDE}$ ) human RBCs by anti-Rh(D) alloantibody eluate (lane $C$ ); autoantibody eluate of patient LM (lane $E$ ); and control eluates $(C)$ (lanes $B$ and $D$ ). Molecular mass markers are shown in lane $A$.

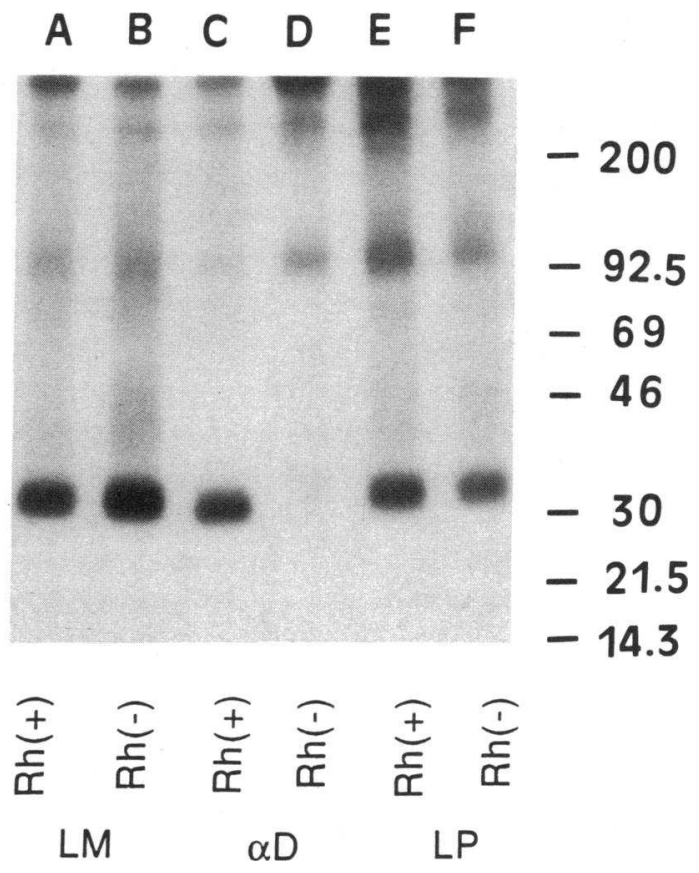

Figure 2. SDS-PAGE autoradiograph of membrane proteins isolated from normal group $\mathrm{O} \mathrm{Rh}(\mathrm{D})$-positive (CDe/CDe) and $\mathrm{Rh}(\mathrm{D})$-negative (ce/ce) RBCs by autoantibody eluate, patient LM (lanes $A$ and $B$ ); anti-Rh(D) alloantibody eluate (lanes $C$ and $D$ ); and autoantibody eluate, patient LP (lanes $E$ and $F$ ). Both LM and LP eluates have isolated $\mathrm{p} 34$ and gp $37-55$.

affinity involves considerable concentration of a minor RBC protein.

As illustrated in Fig. 2 by eluates LM and LP, p34 was isolated by such autoantibodies equally well from D-positive $(\mathrm{O} C \mathrm{CD} / \mathrm{CDe})$ and $\mathrm{D}$ negative ( $\mathrm{O}$ ce/ce) red cells, in contrast to the $\mathrm{Rh}(\mathrm{D})$ polypeptide that was isolated only from D-positive RBCs. Neither p34 nor the Rh(D) polypeptide, however, were detected in concurrent studies of radiolabeled $R h_{\text {null }}$ $\mathrm{RBCs}$, as illustrated by eluate $\mathrm{SH}$ in Fig. $3 a$. Each of six antip34 autoantibody samples tested failed to identify a 34-kD band in $\mathrm{Rh}_{\text {null }} \mathrm{RBCs}$. Allowances were made in such studies for possible unequal radioiodination of paired $R h_{\text {null }}$ and normal cells by loading gels, alternatively, with equal cpm or with equal volumes of the respective elutions from the protein $\mathbf{G}$ beads. Fig. $3 b$ demonstrates that the $\mathrm{Rh}_{\text {null }} \mathrm{RBCs}$ were effectively radioiodinated. Moreover, other autoantibodies, e.g., eluate IB with pure anti-band 3 reactivity in Fig. $3 a$, isolated strongly labeled $\sim 100-\mathrm{kD}$ bands from both $\mathrm{Rh}_{\text {null }}$ and normal RBCs.

Most of the p34-reactive autoantibody eluates (see Table I) produced an additional diffuse autoradiographic "smear" from $\sim 37$ to $55 \mathrm{kD}$ (Figs. 1-3), suggesting variable glycosylation of the target protein. When labeled $\mathrm{Rh}_{\text {null }} \mathrm{RBCs}$ were tested, this heterogeneous smear, like the p34 band, was not evident (Fig. 3 a). Precedent for $\mathrm{Rh}$-related glycoproteins producing polydisperse autoradiographic images over a similar range of molecular mass is discussed below.

The effect of stripping $\mathrm{N}$-linked carbohydrates by treatment of the immunoaffinity-isolated RBC membrane proteins with recombinant $N$-glycanase before SDS-PAGE was tested (see Methods). As expected $(22,23,26)$, this treatment had no 


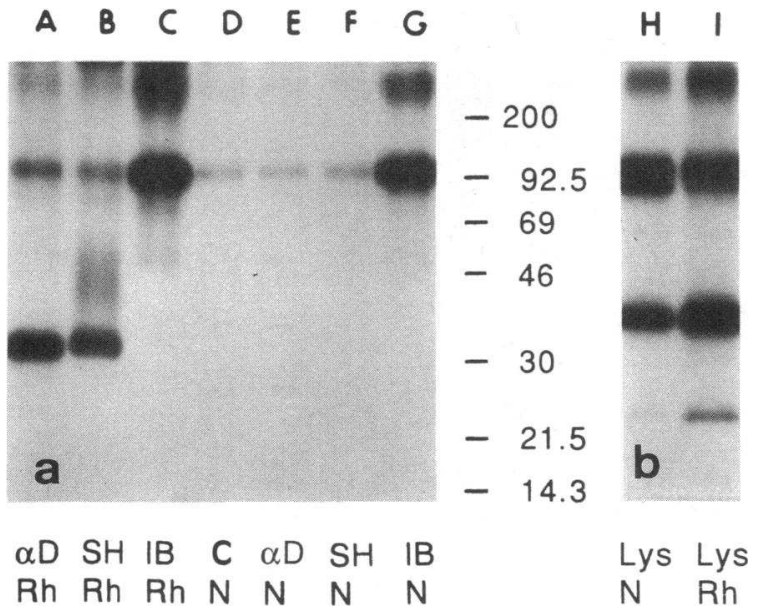

Figure 3. Studies with $\mathrm{Rh}_{\text {null }} \mathrm{RBCs.}$ ( $a$ ) SDS-PAGE autoradiograph of membrane proteins isolated from group O RBCs of common (CDe/ $\mathrm{cDE}$ ) $\mathrm{Rh}$ phenotype (code $R h$ ) or $\mathrm{Rh}_{\text {null }}$ phenotype (code $N$ ) by reaction with anti-Rh(D) alloantibody (lanes $A$ and $E$ ); autoantibody eluate SH (lanes $B$ and $F$ ); autoantibody eluate IB (lanes $C$ and $G$ ); and control eluate (lane $D$ ). (b) Autoradiograph of whole lysates of the ${ }^{125}$ I-labeled $\mathrm{Rh}_{\text {null }}$ (lane $H$ ) and normal (lane $I$ ) RBCs.

effect on the $R h(D)$ polypeptide band obtained with allo-antiD (not shown), nor was there a detectable effect on the mobility or density of the autoantibody-isolated p34 band (Fig. $4 a$ ). However, the polydisperse $37-55-\mathrm{kD}$ smear produced by these same autoantibody eluates disappeared after $N$-glycanase treatment, with the appearance of a sharp new $\sim 31-\mathrm{kD}$ band clearly below the usual position of $\mathrm{p} 34$ (Fig. $4 a$ ) and, in experiments not shown, just below the $\mathrm{Rh}(\mathrm{D})$ polypeptide band. Resolution of this area to reveal this double-band pattern was aided by switching to a $10-20 \%$ gradient gel. The Rh phenotype of the RBC donor had no effect on the autoradiographic pattern observed after $N$-glycanase. The prominent new bands at $\sim 69$ and $90 \mathrm{kD}$ appearing in lanes $B$ and $C$ have not been

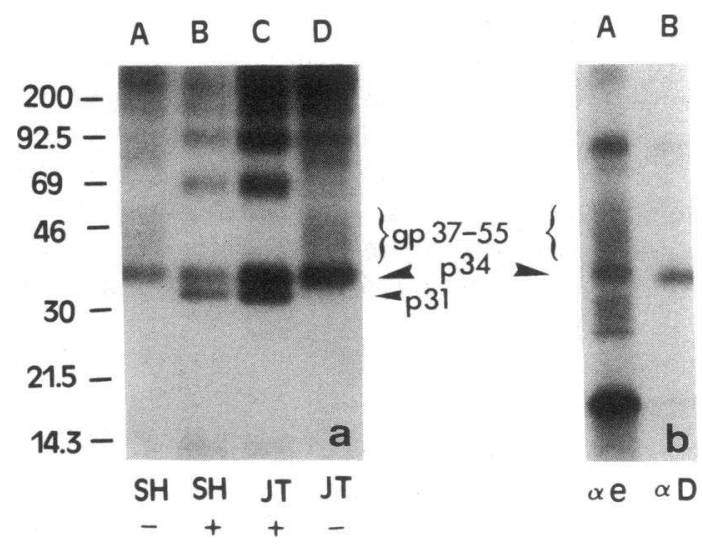

Figure 4. (a) Effect of $N$-glycanase treatment on the SDS-PAGE/autoradiographic patterns of $\mathrm{RBC}$ membrane proteins isolated by autoantibody eluates SH and JT. + , incubation $\left(4 \mathrm{~h}, 37^{\circ} \mathrm{C}\right)$ with $\mathrm{N}$-glycanase; -, concurrent incubation in buffer alone. $(b)$ Comparative autoradiographic patterns of membrane proteins from $\mathrm{O} \mathrm{CDe} / \mathrm{CDe}$ RBCs isolated by IgG anti-e and anti-D alloantibodies without $N$-glycanase treatment. fully characterized but may result from the (4-h) action of $\mathrm{N}$ glycanase on band 3 or its multimers. In separate experiments (not shown) bands of similar molecular mass became evident when whole lysates of unsensitized ${ }^{125}$ I-RBCs were treated with $\mathrm{N}$-glycanase ( $4 \mathrm{~h}$ ) before SDS-PAGE/autoradiography. Such bands were much less prominent after shorter incubations with $N$-glycanase (see below, Fig. 5).

Multiple experiments with $N$-glycanase were run both in 10-20\% gels, in which the new $\sim 31-\mathrm{kD}$ band was consistently separable from what appeared to be typical p34 and in our standard $8-16 \%$ gels, wherein p34 and $\mathrm{Rh}(\mathrm{D})$ polypeptide maintain their typical relative positions but the "new" deglycosylated protein appeared as a downward broadening of the p34 band with incomplete resolution into two bands (not shown). We propose that the lower $(\sim 31-\mathrm{kD})$ band is the deglycosylated form of a variably glycosylated membrane glycoprotein (gp37-55) responsible for the polydisperse smear observed in untreated samples. This protein is apparently distinct from $\mathrm{p} 34$ since their deglycosylated polypeptides differ in $M_{\mathrm{r}}$ under appropriate gel conditions (Fig. $4 a$ ). The possibility that the 31-kD component in the double band (Fig. $4 a$ ) represents a glycanase-induced shift of $\mathrm{p} 34$ itself whereas the 34-kD component arises by deglycosylation of gp37-55 is made most unlikely by kinetic studies with $N$-glycanase presented below.

Other investigators have demonstrated that alloantibodies to the $\mathrm{E} / \mathrm{e}$ or $\mathrm{C} / \mathrm{c} \mathrm{Rh}$ proteins produce both sharp 33-34kD polypeptide bands $(23,27)$ plus polydisperse glycoprotein smears over a range of $M_{\mathrm{r}}$ similar to that produced by our autoantibodies (27) and that these E/e- or C/c-related patterns generally differ from the patterns observed with the $\mathrm{Rh}(\mathrm{D})$ polypeptide $(23,27,28)$ or D-related glycoprotein (27). In our hands, allo-anti-e isolated both a 34-kD band indistinguishable from the autoantibody-isolated p34 polypeptide and a polydisperse smear that closely resembled autoantibodyproduced gp37-55 (Fig. $4 b$ ). Neither of these proteins was isolated by allo-anti-e from radiolabeled $\mathrm{O} \mathrm{cDE} / \mathrm{cDE} \mathrm{RBCs}$ (not shown), whereas p34 and gp37-55 could be isolated by autoantibodies from RBCs of any common Rh phenotype. The effect of deglycosylation on these anti-e-isolated proteins was identical to that just demonstrated (Fig. $4 a$ ) with autoantibody-isolated p34 and gp37-55. This is illustrated in Fig. 5 in which an autoantibody eluate (JT) recognizing p34 and gp3755 was tested in parallel with allo-anti-e in a kinetic study with $N$-glycanase. The stepwise disappearance of the glycoprotein smears and emergence of the $\sim 31-\mathrm{kD}$ deglycosylated polypeptide displayed strikingly similar time courses (Fig. 5).

The three bands appearing in the 24-29-kD region of lane $A$ in Fig. $4 b$ were not a consistent finding with anti-e (e.g., see Fig. 5). We have occasionally seen such 24-29-kD bands with other $\mathrm{Rh}$ allo- or autoantibodies but not in a reproducible fashion. Whether such lower mol wt bands are related in any way to the truncated $\mathrm{Rh}$ mRNA isoforms recently reported by Kim et al. (29) cannot be resolved without systematic study.

We were unable to obtain a sufficiently potent or high affinity anti-c or anti-C to permit us to compare the $\mathrm{Rh} C / \mathrm{c}$ proteins in the same assays.

Band 3. A completely different pattern of membrane protein isolation was exhibited by the autoantibodies of 11 other AHA patients (IB through CV in Table I). Their autoradiographs consistently displayed an intense $\sim 100-\mathrm{kD}$ band with no detectable isolation of p34 (eluate IB, Fig. $3 a$ ). In contrast to $\mathrm{p} 34$, this $100-\mathrm{kD}$ protein was isolated equally well from 


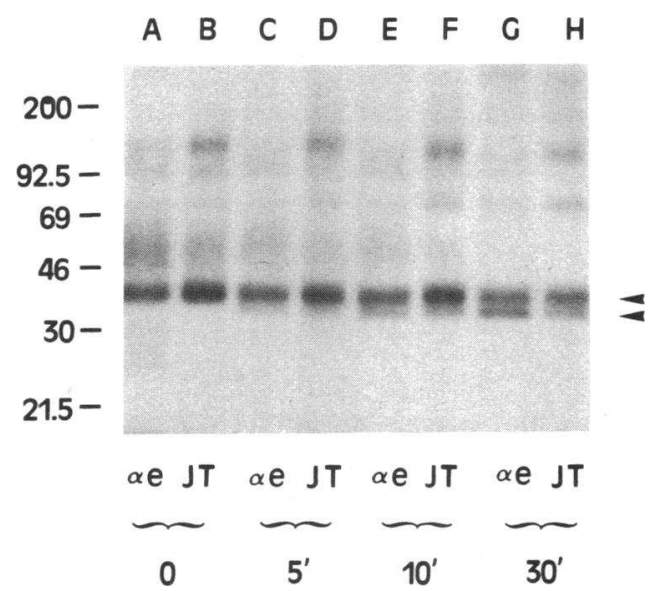

Figure 5. Kinetic study with $\mathrm{N}$-glycanase comparing effects on membrane proteins isolated from $\mathrm{O}$ ce/ce RBCs by IgG allo-anti-e and autoantibody eluate JT. The arrowheads mark the position of p34 or e polypeptide and of the enzyme-induced product termed $\mathrm{p} 31$.

$\mathrm{Rh}_{\text {null }}$ and normal RBCs (Fig. $3 a$ ). This autoantibody-isolated 100-kD band appeared indistinguishable from the autoradiographic band isolated from the same labeled RBCs by rabbit anti-band 3 serum (not shown). Moreover, when this 100-kD protein was initially isolated from ${ }^{125}$ I-labeled RBCs by appropriate human autoantibody eluates, subjected to SDS-PAGE, and then electroblotted to nitrocellulose (NC), development of the blot with specific rabbit antiband 3 (Fig. $6 b$ ) revealed a $100-\mathrm{kD}$ band corresponding to the position of the autoantibody-isolated $100-\mathrm{kD}$ band visualized by autoradiography (Fig. 6 a). Such 100-kD bands, moreover, coincided electrophoretically with a major radioiodinated protein of the same apparent molecular mass in whole RBC lysates (Fig. $6 a$ ), as

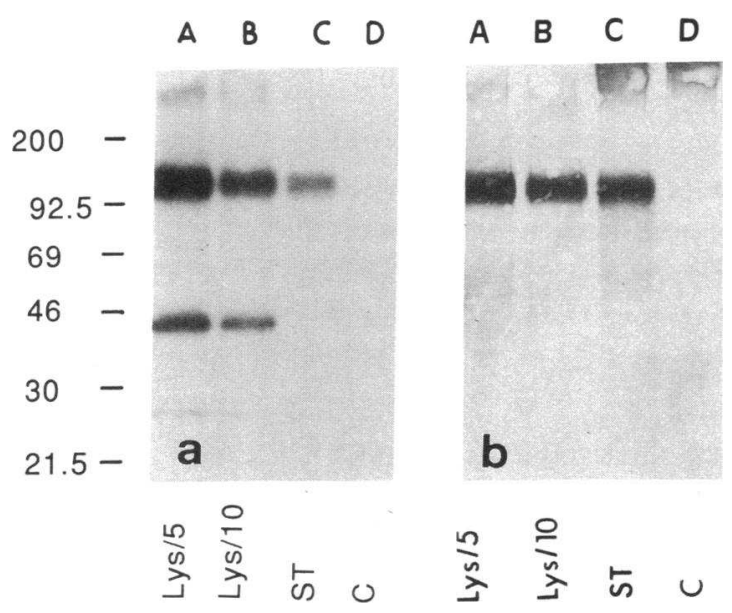

Figure 6. Identification of band 3. (a) Autoradiograph of the nitrocellulose electroblot from SDS-PAGE separation of 1:5 and 1:10 dilutions of whole RBC lysate (lanes $A$ and $B$ ) and of membrane proteins affinity isolated by autoantibody eluate ST (lane $C$ ) and by a control eluate (lane $D)$. ( $b$ ) ELISA development of the same NC blot by sequential addition of specific rabbit antiserum to human band 3 , horseradish peroxidase-goat anti-rabbit IgG, and 4-chloro-1naphthol substrate. would be expected for band 3 . The 41-kD bands in lanes $A$ and $B$ (Fig. $6 a$ ) represent GPA that was not detectably isolated by ST eluate from this bleeding date.

It should be noted that essentially all of our autoradiographs contained a band of varying density in the band 3 area, including faint "background" bands observed with the following controls: substitution of normal control eluates (see Methods) for autoantibody eluates in the initial coating of the intact ${ }^{125}$ I-labeled RBCs; use of D-negative RBCs in studies with antiD eluates, a pairing that yields no detectable 32-kD Rh(D) band; and omission of all anti-RBC antibody sources and incubating unsensitized ${ }^{125} \mathrm{I}-\mathrm{RBC}$ lysates with protein $\mathrm{G}$ beads. This experience agrees with that of other workers who have also commented on the ubiquity of background quantities of band 3 in autoradiographs (23). This does not mean, however, that the very dense autoradiographic bands obtained with many of the autoantibody eluates just discussed are nonspecific. These bands reproducibly stood out from the "background" bands observed with the controls. On the other hand, weak band 3 images obtained with other autoantibody eluates, which were not distinguishable from those produced by concurrently run control eluates, were omitted in compiling the summary data in Table I.

The very high mol wt bands seen in some autoradiographs presumably represent aggregates of band 3 , which has a known propensity to aggregate under these conditions (30).

$G P A$. Another specificity was suggested by the reproducible appearance of sharp bands with a $M_{\mathrm{r}}$ of $41 \mathrm{kD}$ in autoradiographs from certain AHA patients (Fig. $7 a$ and Table I). The $\sim 41-\mathrm{kD}$ protein isolated by these autoantibodies coincided with the position of GPA when whole lysates of ${ }^{125}$ I-RBCs were analyzed in the same gels (Fig. $7 a$ ). The affinity-isolated proteins from two of these patients (SS and GF) were electrotransferred from the SDS-PAGE gel to NC and the 41-kD bands were confirmed as GPA monomer by reactivity with specific $\mathrm{mAb}$ (Fig. $7 \mathrm{~b}$ ). In addition, higher molecular mass bands of GPA dimer were now clearly recognizable in positions just below band 3 (Fig. $7 b$ ). $N$-glycanase treatment of autoantibodybound GPA produced a shift to a lower molecular mass but had no effect on the intensity of the GPA bands in direct autoradiographs of SDS-PAGE gels (not shown).

None of the eluates immunoprecipitated GPA alone (Table I). For this reason we had some concern that its appearance in our autoradiographs might reflect nonspecific coprecipitation of this abundant RBC protein with specific immune complexes involving band 3 or p34 plus gp37-55. On the other hand, isolation of GPA was found only with certain AHA eluates and was reproducible. Moreover, GPA was not detectably coprecipitated by some of our most potent antiband 3 or anti-p34 eluates (Figs. 1-6 and Table I).

We will discuss below the possibility that eluates that isolate both GPA and band 3 might have specificity for the $\mathrm{Wr}^{\mathrm{b}}$ antigen, which is thought to be formed by a GPA-band 3 interaction (31). The coisolation of these two proteins by a significant proportion of our patients ( Table I) recalls their coisolation by mouse monoclonal anti- $\mathrm{Wr}^{\mathrm{b}}(31)$.

$\alpha$-Methyldopa $(\alpha-M D)$ associated autoantibodies. The autoantibody populations listed in Table I were from "spontaneously arising" AHA cases. Three additional autoantibody eluates were available, in frozen storage, from patients whose hemolytic anemia had been associated with $\alpha$-MD therapy. These eluates, which were less potent by IAT than the "sponta- 


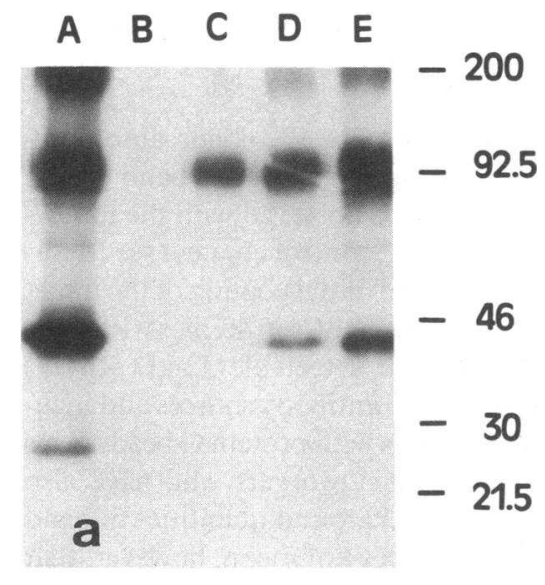

Lys C ST SS GF

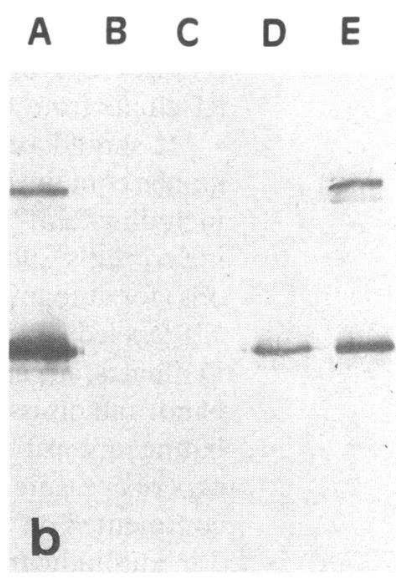

LyS C ST SS GF
Figure 7. Identification of GPA. (a) Autoradiograph of the NC electroblot from SDS-PAGE separation of whole $\mathrm{RBC}$ lysate (lane $A$ ) and of membrane proteins affinity isolated by autoantibody eluates ST, SS, and GF (lanes $C-E$ ). Eluate ST was from a date of bleeding (see below) that displayed strong reactivity with band 3 but no detectable isolation of GPA. Products derived with a control eluate were run in lane $B$. $(b)$ ELISA development of the same NC blot by murine mAb to GPA, horseradish peroxidase-goat anti-mouse IgG, and substrate. neous" AHA eluates studied, each isolated weak but definite 34-kD bands that were electrophoretically indistinguishable from p34 coisolated from the same RBCs in the same gel by "spontaneous" AHA autoantibodies (not shown). Trace quantities of gp37-55 were also present; after $N$-glycanase treatment a sharp 31-kD band emerged in addition to p34.

Correlation with serological reactions against intact red cells. Table I (last two columns) summarizes data on IAT reactions of the autoantibodies with intact RBCs of normal and $\mathrm{Rh}_{\text {null }}$ phenotypes. Eluates that strongly isolated band 3 protein alone or in combination with GPA in the immunoaffinity assays reacted strongly and equally with both intact normal and $\mathrm{Rh}_{\text {null }} \mathrm{RBCs}$. Conversely, a majority of the autoantibody eluates that mediated a prominent isolation of p34 displayed either negative or clearly weaker IAT reactions with $R h_{\text {null }}$ cells. There were two exceptions. The eluate of patient LP appeared to isolate both p34 and band 3 but did not react with $R h_{\text {null }}$ RBCs by IAT in the dilutions tested. Conversely, patient CR displayed equal reactivity with $R h_{\text {null }}$ and normal $R B C s$ by IAT despite the fact that her immunoaffinity results with labeled RBCs had suggested both anti-p34 and anti-band 3 specificities. It is possible that anti-band 3 (in patient CR) and anti-p34 (in patient LP) are more dominant in the original eluate than was reflected in the autoradiographic patterns. Perhaps the autoradiographic image of band 3 produced by LP eluate is nonspecific despite our careful effort to distinguish background from specific bands. Alternatively, patient CR could have still another autoantibody population reactive with an RBC antigen that is not radioiodinated under our conditions. Not shown in Table I is the fact that in each of our three $\alpha$-MD-associated cases the autoantibodies were selectively unreactive with $R h_{\text {null }}$ RBCs, in keeping with their isolation of p34 and gp37-55.

\section{Discussion}

By means of an immunoaffinity procedure using purified autoantibodies (RBC eluates) and surface-radiolabeled human RBCs with analysis by SDS-PAGE/autoradiography, the IgG (warm-reacting) anti-RBC autoantibodies of 20 AHA patients have been used to identify erythrocyte membrane proteins potentially serving as target autoantigens. Our results indicate that at least four single-chain proteins may fulfill this role. Two appear to be members of the Rh family. One, which we have provisionally designated $\mathrm{p} 34$ on the basis of its apparent molecular mass, appears to be a minor $\mathrm{RBC}$ membrane protein; is lacking or severely deficient in $\mathrm{Rh}_{\text {null }} \mathrm{RBCs}$; was consistently distinguishable by its slightly higher molecular mass from the well-studied 32-kD Rh(D) polypeptide; and, like the $R h(D)$ polypeptide, is judged to be a nonglycosylated polypeptide on the basis of the studies with $N$-glycanase (Figs. $4 a$ and 5).

The second apparently Rh-related protein identified by these autoantibodies appears to be a variably glycosylated glycoprotein (termed gp37-55), which was also deficient in $\mathrm{Rh}_{\text {null }}$ RBCs. Such a protein has a well-documented precedent in the $\mathrm{Rh}$-related glycoproteins $(27,32,33)$. The latter are reported to have differing $\mathrm{NH}_{2}$-terminal sequences from the nonglycosylated $\mathrm{Rh}$ polypeptides ( 32 ) and to produce polydisperse autoradiographic patterns over a range of molecular mass encompassing the 37-55-kD smear isolated by our autoantibody eluates (Figs. 1-5). Such Rh-related glycoproteins have been isolated both by anti-D, anti-c, or anti-E alloantibodies (27) and by certain murine mAbs reactive with $\mathrm{Rh}$ proteins (32). For reasons not yet clear, such polydisperse radiographic images were not observed in our many studies with anti$\mathrm{Rh}$ (D) eluates tested concurrently with our anti-p34 autoantibody eluates (Figs. 1, 2, $3 a$, and $4 b$ ).

In the present study, deglycosylation of gp37-55 yielded a polypeptide of $M_{\mathrm{r}} \sim 31 \mathrm{kD}$ that was electrophoretically separable from $N$-glycanase-treated p34 and, therefore, gp37-55 is apparently a distinct protein rather than glycosylated variants of p34. GP37-55 was observed in our autoradiographs only when p34 was also evident. The converse, i.e., the appearance of the p34 band without the gp37-55 smear, occurred only with weaker anti-p34 eluates (Table I) and could well be a quantitative phenomenon, reflecting the greater difficulty in visualizing a polydisperse pattern. Whether the autoantibodies reactive with p34 and gp37-55 recognize shared or differing epitopes on these two proteins is not yet clear. The possibility also exists that only one of these two proteins, p34 or gp37-55, carries the relevant autoepitope(s) and that the other protein is coprecipitated because of noncovalent bonding to the epitopebearing protein. Alternatively, it is conceivable that the autoantigenic epitope results from an interaction of these two proteins ( see discussion of $\mathrm{Wr}^{\mathrm{b}}$ below). Such points had been 
raised earlier with respect to the glycoproteins isolated by $\mathrm{Rh}$ alloantibodies or Rh-related mAbs $(11,32,33)$.

As noted earlier, $\mathrm{Rh}_{\text {null }} \mathrm{RBCs}$ are deficient in proteins other than the Rh family. Thus, our inability to detect p34 and gp3755 in $\mathrm{Rh}_{\text {null }} \mathrm{RBCs}$ does not in itself provide unambiguous evidence that these proteins belong to the Rh family. However, there are other observations consistent with this interpretation. The $\mathrm{Rh}$ polypeptides are thought to be virtually unique among membrane proteins in being nonglycosylated (33) and p34 appears to have this property. On the other hand, gp37-55 is remarkably similar to the $\mathrm{Rh}$-related glycoproteins, particularly those isolated by anti-c and anti-E (27) and by anti-e (Figs. 4 and 5 ). Moreover, a large body of serological data had strongly suggested that one or more proteins of the $\mathrm{Rh}$ complex serve as target antigens in many cases of AHA $(6-10,13)$ and in the great majority of $\alpha$-MD-associated autoantibodies (34).

Extrapolating from our findings in the light of recent advances in our molecular understanding of the Rh system (33), we propose but have not proven that $\mathrm{p} 34$ and the $33-34-\mathrm{kD}$ polypeptide carrying the $\mathrm{Rh} \mathrm{E} / \mathrm{e}$ alloantigens are the same molecule, but with the autoantibodies recognizing a public epitope distinct from the $\mathrm{E} / \mathrm{e}$ alloantigenic epitopes. The similarity of autoantibody-isolated gp37-55 to the diffuse glycoprotein isolated by anti-e alloantibody is striking (Fig. 5). We could not adequately test this hypothesis in relation to the $\mathrm{Rh} C / \mathrm{c}$ proteins but, given the close structural similarity of $\mathrm{C} / \mathrm{c}$ and $\mathrm{E} / \mathrm{e}$ polypeptides ( 35 ) and their possible encoding by a single gene (36), we suspect that autoreactive epitope(s) may prove to be present on $\mathrm{C} / \mathrm{c}$ as well as $\mathrm{E} / \mathrm{e}$. This concept would fit with observations that the $\mathrm{C} / \mathrm{c}$ and $\mathrm{E} / \mathrm{e}$ polypeptides share (with p34) a slightly higher apparent molecular mass than the D polypeptide $(23,27,28)$ and with the accumulated serological experience that when RBC autoantibodies exhibit apparent specificity for individual $\mathrm{Rh}$ antigens (i.e., those defined by alloantibodies), it has frequently been for $\mathrm{E} / \mathrm{e}$ or $\mathrm{C} / \mathrm{c}$ but rarely for $\mathrm{D}(2,6-8,13)$. Alternatively, it cannot be excluded that p34 and gp37-55 could be distinct from any of the known alloantigen-expressing proteins of the $\mathrm{Rh}$ complex but still members of the $\mathrm{Rh}$ family. It is of much theoretical interest that, in each of three patients whose AHA was induced by $\alpha$-MD therapy, autoantibodies to p34 and to gp37-55 were also found. Whether anti-p34 antibodies arising in the setting of $\alpha$-MD therapy recognize precisely the same epitope(s) on these proteins as those occurring in "spontaneous" AHA remains to be seen.

Despite two exceptions noted above, autoantibody-mediated isolations of RBC membrane proteins correlated well with their serological reactivity against normal and $R h_{\text {null }}$ RBCs (Table I). These observations may serve as a first step toward a molecular understanding of these long-recognized differences in serological behavior among AHA autoantibodies.

Two other RBC membrane proteins that are not members of the $\mathrm{Rh}$ family have also been identified as candidate autoantigens in our studies, the band 3 anion transporter and GPA. Band 3 appeared to be the sole or dominant specificity in seven cases and in many others was found in combination with antiGPA or with anti-p34 or both (see Table I). The issue of nonspecific autoradiographic images of band 3 was addressed in Results. Having used control eluates in nearly every experiment as "noise" monitors, we feel that the band 3 isolations illustrated in Figs. 3 and 6 and summarized in Table I are genuine. Victoria et al. (19) have also reported autoantibody reactivity with band 3 in 12 AHA patients. Their study did not implicate other $\mathrm{RBC}$ membrane proteins as potential autoantigens in AHA.

The final membrane protein identified by these patients' autoantibodies was GPA. For the reasons given in Results, we do not regard the presence of GPA in our autoradiographs to be nonspecific. Isolation of this protein is consistent with evidence that GPA carries the En ${ }^{a}$ antigen (37) and interacts with band 3 to form the $\mathrm{Wr}^{\mathrm{b}}$ antigen (31). Both had been identified serologically as non-Rh specificities in $\operatorname{AHA}(13,14)$, with anti$\mathrm{Wr}^{\mathrm{b}}$ being relatively common (13). Unfortunately, RBCs of the very rare $\mathrm{Wr}(\mathrm{a}+\mathrm{b}-)$ or $\mathrm{En}^{\mathrm{a}}(-)$ phenotypes were not available for concurrent study.

Murine monoclonal anti-Wr ${ }^{\mathrm{b}}$ isolates both GPA and band 3 from radiolabeled $R B C s$ ( 31 ). On this basis the last six patients listed in Table I and, more weakly, patients JT and RE, all of whose autoantibodies isolated both GPA and band 3, might have anti-Wr $\mathbf{r}^{\mathbf{b}}$ alone or in combination with other antibodies. In Issitt et al.'s ( 13) series, most auto-anti-Wr ${ }^{\mathrm{b}}$ antibodies were accompanied by other specificities. The presence of "pure" anti-Wr ${ }^{b}$ in our own cases is perhaps made less likely by the finding that all five of the eluates that strongly isolated both GPA and band 3 were from patients who exhibited in vivo C3 binding to their RBCs (Table I) whereas Issitt et al. (13) concluded that none of their four examples of pure anti-Wrb autoantibodies was complement fixing.

In one of our patients (ST), from whom multiple eluates were available over a multiyear period, a change in reactivity with GPA or in the ratio of anti-GPA to antiband 3 appeared to occur without a major change in reactivity with band 3 or a correlating shift in total IgG content of eluates. This suggests that autoantibodies reactive with GPA and those reactive with band 3 may vary independently in some instances. Anti- $\mathrm{Wr}^{\mathrm{b}}$ (or another antibody reactive with GPA) might have been produced at certain times in the patient's course but other antibodies apparently reactive with band 3 itself dominate throughout. Similarly, patients IB, AR, RL, BH, and FY (Table I), whose eluates consistently and strongly isolated band 3 alone, appear to have a distinct specificity whose serological counterpart, if there is one, remains to be clarified. The biochemical correlates of the entire group of non- $\mathrm{Rh}$-related autoantibody specificities clearly require further study.

\section{Acknowledgments}

We thank Drusilla Wemett for valued technical assistance, and Lynn Kosarko and Laurie O'Dea for skillful manuscript preparation. Special thanks are due to Dr. Neil Blumberg, Ann McMican, and Mary T. Cox and staff of the Strong Memorial Hospital Blood Bank faculty for their immensely valuable cooperation and help with reagents and patient identification. Insightful discussions of band 3 and of $R \mathrm{~h}$ proteins were kindly provided by Dr. Philip Knauf (University of Rochester) and Dr. Peter Agre (Johns Hopkins University), respectively. This study would not have been possible without the kind cooperation of the many physicians who made their patients known to us or assisted in the acquisition of blood samples. Finally, we are indebted to the AHA patients whose consent to be studied was generously given.

This investigation was supported by U. S. Public Health Service research grants 5-R01-AG-08178 and 3-P01-AI-29522.

Note added in proof. While this manuscript was under review, Barker et al. ( $B r$. J. Haematol. 1992. 82:126-132) reported the isolation, by a nonradioisotopic method, of a $32-\mathrm{kD}$ polypeptide plus a $38-51-\mathrm{kD}$ diffuse protein zone by the autoantibodies of three AHA 
patients. These proteins appear to be very similar to our p34 and gp37-55.

One of the Rh-related glycoproteins has now been cloned and sequenced, and exhibits close sequence homology to the $\mathrm{Rh}$ polypeptides (Ridgwell, K., et al. 1992. Biochem. J. 287:223-228).

\section{References}

1. Leddy, J. P., J. L. Falany, and S. I. Rosenfeld. 1992. Erythrocyte membrane proteins reactive with human (warm-reacting) anti-red cell autoantibodies. Clin Res. 40:199a. (Abstr.)

2. Dacie, J. V. 1962. The Haemolytic Anaemias, Congenital and Acquired. Part II. The Autoimmune Haemolytic Anaemias. 2nd ed. Grune and Stratton, New York. 718 pp.

3. Dameschek, W., E. Witebsky, and F. Milgrom, editors. 1965. Autoimmunity-Experimental and Clinical Aspects. Ann. NY Acad. Sci. 124:415-498.

4. Jandl, J. H., A. Richardson-Jones, and W. B. Castle. 1957. The destruction of red cells by antibodies in man. I. Observations on the sequestration and lysis of red cells altered by immune mechanisms. J. Clin. Invest. 36:1428-1459.

5. Frank, M. M., A. D. Schreiber, J. P. Atkinson, and C. J. Jaffe. 1977 Pathophysiology of immune hemolytic anemia. Ann. Intern. Med. 87:210-222.

6. Petz, L. D., and G. Garratty. 1980. Acquired Immune Hemolytic Anemias Churchill Livingstone, New York. pp. 232-266.

7. Weiner, W., and G. H. Vos. 1963. Serology of acquired hemolytic anemia Blood. 22:606-613

8. Dacie, J. V., and S. M. Worlledge. 1969. Auto-immune hemolytic anemias Progr. Hematol. 6:82-120.

9. Vos, G. H., L. Petz, and H. H. Fudenberg. 1970. Specificity of acquired haemolytic anaemia autoantibodies and their serological characteristics. $B r . J$. Haematol. 19:57-66.

10. Leddy, J. P., P. Peterson, M. A. Yeaw, and R. F. Bakemeier. 1970. Patterns of serologic specificity of human $\gamma \mathrm{G}$ erythrocyte autoantibodies. J. Im munol. 105:677-686.

11. Avent, N., P. A. Judson, S. F. Parsons, G. Mallinson, D. J. Anstee, M. J. A Tanner, P. R. Evans, E. Hodges, A. G. Maciver, and C. Holmes. 1988. Monoclonal antibodies that recognize different membrane proteins that are deficient in $\mathbf{R h}$ null human erythrocytes. Biochem. J. 251:499-505.

12. Issitt, P. D., and B. G. Pavone. 1978. Critical reexamination of the specificity of auto-anti-Rh antibodies in patients with a positive direct antiglobulin test. Br. J. Haematol. 38:63-74.

13. Issitt, P. D., B. G. Pavone, D. Goldfinger, H. Zwicker, C. H. Issitt, J. A. Tessel, S. W. Kroovand, and C. A. Bell. 1976. Anti-W $\mathrm{r}^{\mathbf{b}}$, and other autoantibodies responsible for positive direct antiglobulin tests in 150 individuals. $B r . J$ Haematol. 34:5-18.

14. Bell, C. A., and H. Zwicker. 1978. Further studies on the relationship of anti-En ${ }^{\mathrm{a}}$ and anti-Wr ${ }^{\mathrm{b}}$ in warm autoimmune hemolytic anemia. Transfusion (Arlingt.). 18:572-575.

15. Celano, M. J., and P. Levine. 1967. Anti-LW specificity in autoimmune acquired hemolytic anemia. Transfusion (Arlingt.). 7:265-268.

16. Marsh, W. L., M. E. Reid, and E. P. Scott. 1972. Autoantibodies of U blood group specificity in autoimmune haemolytic anaemia. Br. J. Haematol. 22:625-629.

17. Marsh, W. L., R. Oyen, E. Alicea, M. Linter, and S. Horton. 1979. Autoimmune hemolytic anemia and the Kell blood groups. Am. J. Hematol. 7:155162.
18. Leddy, J. P., N. B. Whittemore, and R. I. Weed. 1970. Human erythrocyte membranes: effect of lipid extraction on binding of IgG ("warm") autoantibodies and $\mathrm{Rh}$ isoantibodies. Vox Sang. 19:444-450.

19. Victoria, E. J., S. W. Pierce, M. J. Branks, and S. P. Masouredis. 1990. IgG red blood cell autoantibodies in autoimmune hemolytic anemia bind to epitopes on red blood cell membrane band 3 glycoprotein. J. Lab. Clin. Med. 115:74-88.

20. Wakui, H., I. Hirokazu, R. Kobayashi, H. Itoh, T. Notoya, K. Yoshida, Y. Nakamoto, and A. B. Miura. 1988. Autoantibody against erythrocyte protein 4.1 in a patient with autoimmune hemolytic anemia. Blood. 72:408-412.

21. Bigbee, W. L., M. Vanderlaan, S. S. N. Fong, and R. H. Jensen. 1983. Monoclonal antibodies specific for the $\mathrm{M}$ - and $\mathrm{N}$ - forms of human glycophorin $\mathrm{A}$. Mol. Immunol. 20:1353-1362.

22. Gahmberg, C. G. 1982. Molecular identification of the human Rho(D) antigen. FEBS (Fed. Eur. Biochem. Soc.) Lett. 140:93-97.

23. Moore, S., C. F. Woodrow, and D. B. L. McClelland. 1982. Isolation of membrane components associated with human red cell antigens $\mathrm{Rh}(\mathrm{D}),(\mathrm{c}),(\mathrm{E})$ and Fy ${ }^{\mathbf{a}}$. Nature (Lond.). 295:529-531.

24. Laemmli, U. K. 1970. Cleavage of structural proteins during the assembly of the head of bacteriophage T4. Nature (Lond.). 227:680-685.

25 . Weber, K., and M. Osborn. 1969. The reliability of molecular weight determinations by dodecyl sulfate-polyacrylamide gel electrophoresis. J. Biol. Chem. 244:4406-4412.

26. Gahmberg, C. G. 1983. Molecular characterization of the human red cell Rho(D) antigen. EMBO (Eur. Mol. Biol. Organ.) J. 2:223-227.

27. Moore, S., and C. Green. 1987. The identification of specific Rhesus-polypeptide-blood-group-ABH-active glycoprotein complexes in the human red cell membrane. Biochem. J. 244:735-741.

28. Suyama, K., and J. Goldstein. 1988. Antibody produced against isolated $\mathrm{Rh}$ (D) polypeptide reacts with other Rh-related antigens. Blood. 72:1622-1626.

29. Kim, C. L. V., B. Cherif-Zahar, V. Raynal, I. Mouro, M. Lopez, J.-P. Cartron, and Y. Colin. 1992. Multiple Rh messenger RNA isoforms are produced by alternative splicing. Blood. 80:1074-1078.

30. Steck, T. L. 1978. The band 3 protein of the human red cell membrane: a review. J. Supramol. Struct. 8:311-324.

31. Telen, M. J., and J. A. Chasis. 1990. Relationship of the human erythrocyte $\mathrm{Wr}^{\mathrm{b}}$ antigen to an interaction between glycophorin $\mathrm{A}$ and band 3. Blood. 76:842-848.

32. Avent, N. D., K. Ridgwell, W. J. Mawby, M. J. A. Tanner, D. J. Anstee, and $B$. Kumpel. 1988. Protein-sequence studies on Rh-related polypeptides suggest the presence of at least two groups of proteins which associate with the red-cell membrane. Biochem. J. 256:1043-1046.

33. Agre, P., and J.-P. Cartron. 1991. Molecular biology of the Rh antigens. Blood. 78:551-563.

34. Worlledge, S. M. 1969. Immune drug-induced haemolytic anaemias. Semin. Hematol. 6:181-200.

35. Blanchard, D., C. Bloy, P. Hermand, J.-P. Cartron, A. M. Saboori, B. L. Smith, and P. Agre. 1988. Two dimensional iodopeptide mapping demonstrates that erythrocyte $\mathrm{Rh} \mathrm{D}, \mathrm{c}$ and $\mathrm{E}$ polypeptides are structurally homologous but nonidentical. Blood. 72:1424-1427.

36. Colin, Y., B. Cherif-Zahar, C. LeVan Kim, V. Raynal, V. Van Huffel, and J.-P. Cartron. 1991. Genetic basis of the $\mathrm{Rh}(\mathrm{D})$-positive and $\mathrm{Rh}(\mathrm{D})$-negative blood group polymorphism as determined by Southern analysis. Blood. 78:27472752.

37. Tanner, M. J. A., and D. J. Anstee. 1976. The membrane change in En(a-) human erythrocytes. Absence of the major erythrocyte sialoglycoprotein. Biochem. J. 153:271-277. 